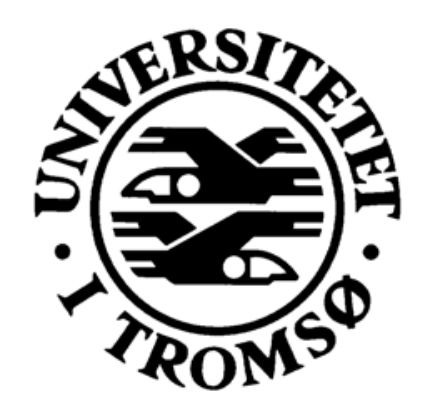

\title{
Efficiency in complementary partnerships with competition
}

\author{
by \\ Jan Yngve Sand \\ Working Paper Series in Economics and Management \\ No. 01/06, January 2006 \\ Department of Economics and Management \\ Norwegian College of Fishery Science \\ University of Tromsø \\ Norway
}




\title{
Efficiency in complementary partnerships with competition
}

\author{
Jan Y. Sand \\ The University of Tromso, Norway
}

December 15, 2005

\begin{abstract}
This paper investigates a market with strictly complementary inputs, with a particular emphasis on how efficiency can be implemented when the productive firms undertake unobservable effort. It is shown that simple linear sharing rules cannot implement socially optimal effort, but a modified linear sharing rule can implement the first-best outcome and a restricted linear sharing rule can be used to implement the second-best outcome. In addition, problems associated with commitment to the sharing rule is discussed.
\end{abstract}

JEL Classification: C72, D20, L23

Keywords: Complements, intermediary, commitment

\section{Introduction}

In many markets end-user products are produced by a combined effort from two or more economic agents providing complementary inputs. Such relationships can be called teams or partnerships. In several applications the partnership consists of agents in two different market segments, where one of the market segments is monopolised whereas the other is a competitive market. In the literature on communication markets the essential facility, typically a network provider, is a monopoly 
whereas the providers of communication services are typically operating in competitive markets. The inputs are complementary and the inputs from both types of firms are necessary in order for consumers to have positive valuations of the products. In rail transport, the infrastructure provider is often a monopoly, and the train operators compete for end-users. The services offered by these two types of firms are complementary, and the value of a train ticket is zero without tracks that the trains can run on. In electricity markets, an end-user requires the services of both a distribution firm and that of electricity providers. The value of one without the other is zero. In the case of electricity and communications markets, it is not uncommon that end-users contract only with a single firm which package the two types of products. This could be either an (independent) intermediary, or one of the firms.

In the present paper I will investigate a stylised setting with two types of productive firms in the model, which I will call platform providers and content providers. In addition there may be an intermediary firm from which end-users purchase the final product. In the model, the productive firms choose effort levels based on proposed sharing rules. The platform services and contents are considered to be complementary products, and the product that interests customers is the composite product. The platform provider is an essential facility for the content providers, and contents and platform services are complementary inputs. The value of the services is strictly positive only if both types of services are supplied in positive amounts. The provider of platform services and content providers thus form a partnership. The intermediary does not provide any value added in terms of the production of the output, and simply collects the different parts of the service to provide a valuable product for end-users. The intermediary may, however, add value in terms of welfare in certain cases. This will, in particular, be the case when the platform provider has no incentive to choose a sharing rule that implements the socially efficient outcome.

It is assumed that the effort of the distribution and content providers cannot be observed. The assumption on non-observability essentially implies that end-users cannot buy the products separately (or at least, that they cannot observe or verify the quality of the individual components). If the (value of) total output is perceived 
to be low this could be either due to lack of effort by the platform provider, or by lack of effort by the content providers. Effort can be thought of as investments undertaken by the firms. A low level of investment in infrastructure can reduce the speed of the network, and consequently lower the value of the bundled service. As an example we could think of real-time applications on UMTS-telephones, such as interactive maps, streaming video, video conferencing etc.. The quality of the realtime application may in itself be very high, but without network bandwidth to cope with the increased capacity requirements the value of the service is low to end-users. A low level of investment in, e.g., compatibility by the content providers reduces the value of the total output. If, for instance, a customer wishes to set up a mobile video call, it is difficult for the caller and the receiver to distinguish which part of the perceived quality that comes from the effort exerted by the network provider to maintain a high capacity, and which part comes from the independent service providers that offer mobile video call services. ${ }^{1}$ Another example of this could be the case where IP connections traverse several network domains. In such a case the quality of the connection (i.e., the bandwidth) is equal to the lowest quality in the chain, and which network is the bottleneck is not observable to others (or at least, it is prohibitively expensive to verify each sub-connection). Yet another example is related to meta search engines and electronic scientific journals. A number of university libraries have a search platform to enable end-users to search through the library's entire collection of electronic journals with a single search (i.e., no need to go through the same search pattern in each of the individual databases of journals). This platform could, for instance, be a combination of MetaLib (search platform) and SFX (platform for providing direct links from the search platform to the individual databases). The content providers are the different electronic journal databases (ScienceDirect, SwetsWise, ProQuest etc.), and the university library is the intermediary. For the end-user (students and faculty) it is difficult to ascertain who is to blame if the overall quality of the service is poor, as this may be due to either poor performance in the platform (due to lack of effort to perfect the platform)

\footnotetext{
${ }^{1}$ It may be easier for a mobile network operator to offer such mobile video call services, since such a firm is better able to offer dedicated capacity for such a service.
} 
or due to poor search facilities in electronic journal library.

As is shown in Holmstrom (1982), a team providing substitute inputs (or, more correctly, no strictly complementary inputs) will not be able to achieve a first-best outcome in the absence of a principal when budget-balance is required, but the presence of a principal may alleviate the sub-optimal solution posed by the budgetbalance requirement. ${ }^{2}$ In the present model, either the platform, the intermediary or end-users may act as a principal. Contrary to the principal introduced in Holmstrom (1982), the budget breaker in the present model may be an active member of the partnership and can through her choice of effort affect total output. Legros and Matthews (1993) show that free-riding in partnerships only causes problems to the extent that the liability of the partners is limited. With unlimited liability, its is shown that efficiency can be approximated using simple mixing strategies. They also show that efficiency is sustainable if the partners actions are perfect complements. This is also the result of Vislie (1994), where it is demonstrated that a linear (budget balancing) sharing mechanism can implement the team's efficient outcome. If participation constraints and limited liability is introduced in a Leontief partnership, Hvide (2001) shows that the results of Legros and Matthews (1993) and Vislie (1994) no longer hold. Hvide (2001) shows that efficiency can be attained by devising a sharing rule that is balanced, satisfies limited liability and incentive compatibility and participation constraints. Hvide (2001) furthermore investigates the effect of uncertainty. If noise is added to joint output, free-riding can be avoided, whereas free-riding is inevitable if noise is added to individual productivity. McAfee and McMillan (1991) show that optimal contracts in a team subject to both adverse selection and moral hazard, are in certain cases linear in the team's output. Furthermore, they show that the outcome is the same whether the principal observes only the total output or the individual team member's effort, and consequently, monitoring is not needed to avoid shirking.

The main contribution of this paper is to analyse the interaction between teams

\footnotetext{
${ }^{2}$ Rasmussen (1987) shows that an efficient budget-balancing contract exists without a budget breaking third party, provided that the punishment can be large enough and that the risk aversion is great enough.
} 


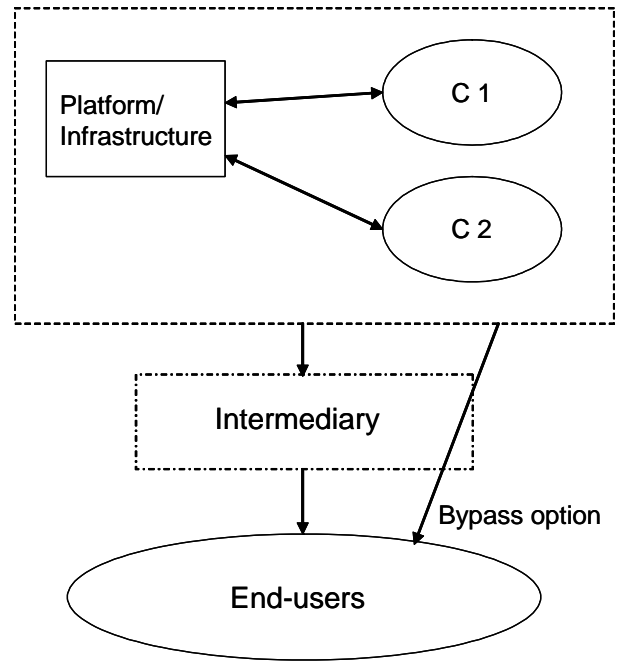

Figure 1:

that provide complementary efforts and teams that provide substitute efforts. The competition in the content market implies, as we will see, that a linear sharing rule no longer can implement first-best efficiency if budget balance is required. The main economic agents in the game and the relationships between them, is portrayed in figure 1. The use of an intermediary in determining how to share the economic outcome of a trading relationship when there is a monopoly platform and competing providers of input via the platform (content) is investigated. This can be seen as the independent "one-stop-shop". We will assume perfect competition between intermediaries, which implies that the intermediary earns zero profit. Any surplus of trade not allocated to the firms will be redistributed to end-users who may earn positive consumers' surplus. The main questions that we attempt to answer are: i) What constitutes efficiency in this market, and how can we achieve this? ii) What is the value of an intermediary firm - can an intermediary solve the potential problem of implementing the socially optimal solution? We will also discuss briefly which structure will emerge; i.e., will there be an intermediary firm in equilibrium, or will the platform provider or the content providers sell directly to end-users?

The rest of the paper is organised as follows: The basic model is described in section 2 and the efficiency conditions are presented. The problem of implementing 
efficiency and sharing rules that may implement efficiency is discussed in section 3. In section 4 some concluding remarks are made.

\section{The model}

Let us assume that total output of the composite product $x$ is given by the deterministic function: $x=F(e)$, where $e \equiv\left(e_{A}, e_{B}, e_{C}\right)$ is the vector of effort exerted by the three firms $A, B$ and $C$. The total output is assumed to be observable, but the individual efforts are not.

Let firm $A$ be the platform (for example, an infrastructure provider or distribution firm), and $B$ and $C$ be complementors (e.g., content providers). The firms face increasing and convex costs of effort, given by the cost function: $v_{i}\left(e_{i}\right)=\varphi_{i} e_{i}^{2} / 2$, for $i=A, B, C$, with $\varphi_{i}>0$ for all $i$. The content providers offer (a potentially joint) output defined by $q=q\left(e_{B}, e_{C}\right)$, where $q$ is a index of the quality of the content offered and $q$ is increasing and concave in effort. The present set-up is a combination of a team where the team members provide effort that are substitute inputs in content production, and a complementary team.

The output of the composite product $x$ can be more precisely defined as:

$$
x=F\left(e_{A}, q\left(e_{B}, e_{C}\right)\right)=\min \left[b_{A} e_{A}, b_{q} q\left(e_{B}, e_{C}\right)\right]
$$

where the parameter $b_{A}$ represents the productivity of firm $A$, and $b_{q}$ is an index that represents the effect on the value of the composite output of increasing the quality of content. The function (1) also defines the value of production.

Since the value of production can be shared by firms and/or the intermediary firm and end-users, we require only the following:

$$
\sum_{i=A}^{C} \alpha_{i}\left(F\left(e_{A}, q\left(e_{B}, e_{C}\right)\right)\right) \leq F\left(e_{A}, q\left(e_{B}, e_{C}\right)\right)
$$

If (2) holds as an equality, the entire value of production is shared by the three firms. If (2) holds as a strict inequality some surplus accrues to either the intermediary or end-users. 
We will in the following focus on linear sharing schemes. Let $\alpha_{i}$ be firm $i$ 's share of (the value of) the total output, where we assume $\sum_{i} \alpha_{i} \leq 1, i=A, B, C$. The pay-off for firm $i$ is given by:

$$
\pi_{i}=\alpha_{i} \min \left[b_{A} e_{A}, b_{q} q\left(e_{B}, e_{C}\right)\right]-v_{i}\left(e_{i}\right)=\alpha_{i} \min \left[b_{A} e_{A}, b_{q} q\left(e_{B}, e_{C}\right)\right]-\varphi_{i} e_{i}^{2} / 2
$$

Due to the strict complementarity in the production function of the composite product, either the (team) content input or the platform input will be a bottleneck in the production of the composite product. The strict complementarity implies, for example, that an increase in the quality of content only adds value if content quality is the bottleneck factor. Along the lines of Vislie (1994) the $\left(e_{A}, q\right)$-space can be divided into two regions. If $b_{A} e_{A}<b_{q} q\left(e_{B}, e_{C}\right)$ then distribution effort is the bottleneck and $b_{A} e_{A}$ will be substituted into the profit function $\pi_{i}=\alpha_{i} b_{A} e_{A}-v_{i}\left(e_{i}\right)$. If $b_{A} e_{A}>b_{q} q\left(e_{B}, e_{C}\right)$, then $\pi_{i}=\alpha_{i} b_{q} q\left(e_{B}, e_{C}\right)-v_{i}\left(e_{i}\right)$.

\section{$2.1 \quad$ Efficiency}

The total surplus obtained from trade is given by:

$$
W(e) \equiv F\left(e_{A}, q\left(e_{B}, e_{C}\right)\right)-\sum_{i} v_{i}\left(e_{i}\right)
$$

Efficiency requires the following:

$$
\begin{gathered}
b_{A} e_{A}^{*}=b_{q} q\left(e_{B}^{*}, e_{C}^{*}\right) \\
e^{*}:=\underset{e}{\arg \max }\left[F\left(e_{A}, q\left(e_{B}, e_{C}\right)\right)-\sum_{i} v_{i}\left(e_{i}\right)\right]
\end{gathered}
$$

where $e^{*}$ is the effort vector that ensures a maximisation of total surplus, eqn. (4). The first efficiency condition, eqn. (5), is a requirement to ensure that no resources are wasted, and which enables us to rewrite the total surplus (4) as a function of the content providers efforts only. We will assume that the total surplus at efficient effort levels is strictly positive: $W\left(e^{*}\right) \equiv F\left(e_{A}^{*}, q\left(e_{B}^{*}, e_{C}^{*}\right)\right)-\sum_{i} v_{i}\left(e_{i}^{*}\right)>0 .^{3}$

Substituting for $e_{A}^{*}=b_{q} q\left(e_{B}^{*}, e_{C}^{*}\right) / b_{A}$ into the objective function yields:

$$
\Psi(e) \equiv F\left(b_{q} q\left(e_{B}, e_{C}\right) / b_{A}, q\left(e_{B}, e_{C}\right)\right)-v_{A}\left(b_{q} q\left(e_{B}, e_{C}\right) / b_{A}\right)-\sum_{j} v_{j}\left(e_{j}\right)
$$

\footnotetext{
${ }^{3}$ It is shown below that this is indeed true in the context of the present model.
} 
where $j=B, C$.

In addition to the requirement imposed by eqn. (5), which in essence ensures that the bundled product of platform and content services is provided efficiently, efficiency requires that content provision is (stand-alone) efficient. The first-order conditions with respect to the effort vector $\left(e_{B}, e_{C}\right)$ implicitly define the optimal effort levels (for $j=B, C$ ): ${ }^{4}$

$$
\frac{\partial \Psi(e)}{\partial e_{j}}=b_{q}\left(1-\frac{v_{A}^{\prime}}{b_{A}}\right) \frac{\partial q}{\partial e_{j}}-v_{j}^{\prime}=0
$$

To simplify the analysis and to obtain closed-form solutions, assume that $v_{i}\left(e_{i}\right)=$ $\varphi_{i} e_{i}^{2} / 2$ and $q\left(e_{B}, e_{C}\right)=\sum_{j} \beta_{j} e_{j}$. This formulation of the (content) quality function is very stylised, but captures the idea that effort undertaken by the content providers are substitutes (if one firm's effort is increased the other can reduce his effort and still remain on the same level of quality; increasing both firms' effort levels increases the level of quality supplied). The marginal effect of effort by the two firms $B$ and $C$ may be different, and one way to think of this is to say that these firms provide vertically differentiated efforts. Without loss of generality, I will assume that $b_{q}$ is normalised to 1 . The efficient effort level is determined by, for $j, k=B, C$, and $j \neq k$ :

$$
\left(1-\frac{\varphi_{A}}{\left(b_{A}\right)^{2}}\left(\beta_{j} e_{j}+\beta_{k} e_{k}\right)\right) \beta_{j}-\varphi_{j} e_{j}=0
$$

The solution for the socially efficient effort levels can be rewritten as:

$$
e_{j}^{*}=\frac{b_{A}^{2} \beta_{j} \varphi_{k}}{b_{A}^{2} \varphi_{B} \varphi_{C}+\varphi_{A}\left(\beta_{B}^{2} \varphi_{C}+\beta_{C}^{2} \varphi_{B}\right)}
$$

From (5) we find the corresponding $e_{A}^{*}$ :

$$
e_{A}^{*}=\frac{b_{A}\left(\beta_{B}^{2} \varphi_{C}+\beta_{C}^{2} \varphi_{B}\right)}{b_{A}^{2} \varphi_{B} \varphi_{C}+\varphi_{A}\left(\beta_{B}^{2} \varphi_{C}+\beta_{C}^{2} \varphi_{B}\right)}
$$

The socially optimal level of content quality can be deduced from (7), and can be written as:

$$
q^{*} \equiv q\left(e_{B}^{*}, e_{C}^{*}\right)=\frac{b_{A}^{2}\left(\beta_{B}^{2} \varphi_{C}+\beta_{C}^{2} \varphi_{B}\right)}{b_{A}^{2} \varphi_{B} \varphi_{C}+\varphi_{A}\left(\beta_{B}^{2} \varphi_{C}+\beta_{C}^{2} \varphi_{B}\right)}
$$

\footnotetext{
${ }^{4}$ The second-order condition is given by: $\frac{\partial^{2} \Psi(e)}{\partial e_{j}^{2}}=b_{q}\left(1-\frac{v_{A}^{\prime}}{b_{A}}\right) \frac{\partial^{2} q}{\partial e_{j}^{2}}-v_{A}^{\prime \prime}\left(\frac{b_{q}}{b_{A}} \frac{\partial q}{\partial e_{j}}\right)^{2}-v_{j}^{\prime \prime}<0$, and is satisfied in an interior equilibrium.
} 
From (7) we observe that the efficient effort level for firm $j$ is increasing in the rival's convexity parameter $\varphi_{k}$ (i.e., the convexity parameter of the other content team member), since these two firms' efforts are substitutes. The optimal effort of firm $j$ is lower the more convex the platform provider's effort cost is. This is due to effort $e_{A}^{*}$ being decreasing in $\varphi_{A}$ and complementarity. Consequently, since higher effort cost implies a lower effort on behalf of the platform provider, efficiency requires that the content quality $q\left(e_{B}^{*}, e_{C}^{*}\right)$ also be reduced. The efficient effort of a content provider may be either increasing or decreasing in the productivity parameters $\beta_{j}$ and $\beta_{k}$ depending on relative productivity levels of the two firms, and that of the platform provider. It can easily be shown that $e_{j}$ is increasing in $\beta_{j}$ only if $b_{A}^{2} \varphi_{j} \varphi_{k}-\varphi_{A}\left(\beta_{j}^{2} \varphi_{k}-\beta_{k}^{2} \varphi_{j}\right)>0$. In addition, it can be shown that the effort of the platform provider is strictly increasing in either content provider's productivity level. If we assume that firm $j$ is the more productive, then this implies that it is the less likely that this firm's efficient effort level increases with $\beta_{j}$. The seems somewhat counterintuitive, but the more productive firm is already exerting a higher level of effort and since effort costs are convex the added value of firm $j$ 's additional effort is outweighed by his effort costs. In this case the less productive firm will have to increase his level of effort since the platform provider increases his effort.

\subsubsection{Observable effort levels}

Assume that the effort levels are observable. Then the efficient outcome defined by (7), (8) and (9) can be implemented by forcing contracts with corresponding compensations for the cost of effort. Total net surplus when implementing the efficient effort vector can be shown to be $W\left(e^{*}\right) \equiv F\left(e_{A}^{*}, q\left(e_{B}^{*}, e_{C}^{*}\right)\right)-\sum_{i} \varphi_{i}\left(e_{i}^{*}\right)^{2} / 2=$ $F\left(e_{A}^{*}, q\left(e_{B}^{*}, e_{C}^{*}\right)\right) / 2$, which is strictly positive for all positive output levels. This surplus can be distributed among the partners, the intermediary and the end-users. Implementation of the efficient effort vector requires knowledge about marginal productivity and the convexity of effort costs, which are assumed to be common knowledge. 


\subsection{Nash equilibrium with a linear sharing rule}

When effort is unobservable, each of the players maximise her own utility given the characteristics of the proposed sharing rule. Maximising (3) with respect to $e_{A}$ after inserting for $b_{A} e_{A}$, we obtain the best-respons function for firm $A$ :

$$
e_{A}\left(\alpha_{A}\right)=\frac{\alpha_{A} b_{A}}{\varphi_{A}}
$$

which yields an identical effort level as is found in Vislie (1994). Consequently, the best-response function for firm $A,(10)$, depends only factors related to firm $A$ (the sharing rule $\alpha_{A}$, the marginal productivity $b_{A}$, and the convexity parameter $\varphi_{A}$ ).

If content is not a bottleneck factor, effort will be reduced until $b_{A} e_{A}=q$ since effort is costly and such effort will have no impact on total production due to strict complementarity. If, on the other hand, we are in the region where content input is the bottleneck, i.e., $b_{A} e_{A}>q\left(e_{B}, e_{C}\right)$, the joint effort of firms $B$ and $C$ is the critical factor. In this region, the profit for firm $A$ is increasing in $e_{j}$, and decreasing in $e_{A}$. Maximising (3) with respect to $e_{j}$, where $j=B, C$ :

$$
\widetilde{e}_{j}\left(\alpha_{j}\right)=\frac{\alpha_{j} \beta_{j}}{\varphi_{j}}
$$

Since overall content quality is additively separable in the effort of the individual content providers, the effort of each team member is independent of the effort level of the competing team member for a given sharing rule. Looking at the content provision provided by the team in the competitive market segment, we observe that each of the content providers will achieve insufficient remuneration at the margin for their efforts since $\alpha_{j}$ must be less than or equal to 1 , and consequently a sub-optimal amount of effort will be exerted in content provision.

In order to ascertain the efficiency of production of the bundled product of content and platform services, we need to ensure that we are in fact on the $b_{A} e_{A}^{*}=$ $q\left(e_{B}^{*}, e_{C}^{*}\right)$-locus. Let us, for illustrative purposes, define the quasi best-response function for $q$ in this region to be the resulting quality of content provision for a given sharing rule $\left(\alpha_{B}, \alpha_{C}\right)$ :

$$
q\left(\alpha_{B}, \alpha_{C}\right)=\frac{\alpha_{B} \beta_{B}^{2}}{\varphi_{B}}+\frac{\alpha_{C} \beta_{C}^{2}}{\varphi_{C}}
$$




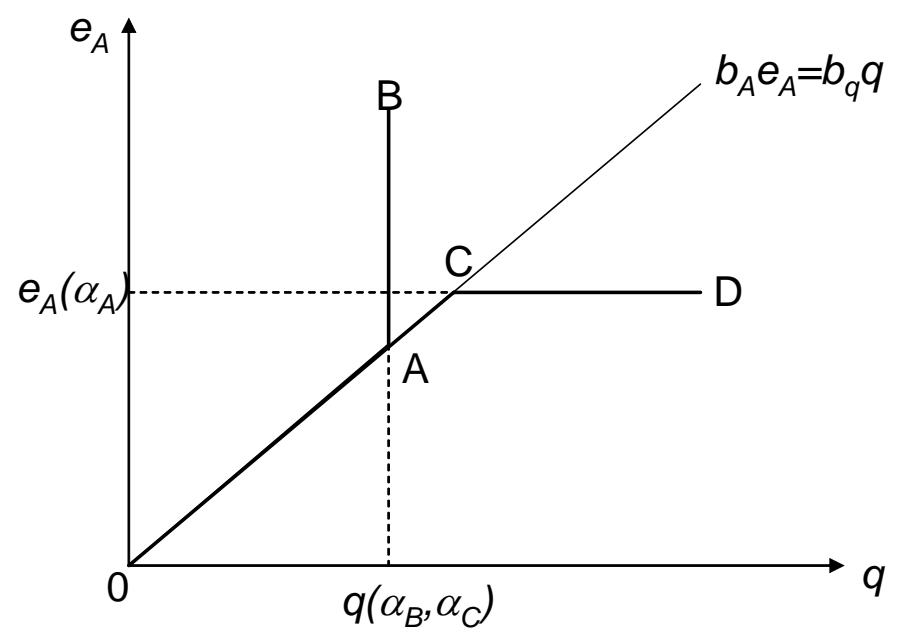

Figure 2:

The quasi-best response function is independent of $e_{A}$ in the region where content provision is the bottleneck factor. In fig. 2 (loosely adapted from Vislie, 1994), the best-response functions for $e_{A}$ and $q$ are illustrated for a given set of $\left(\alpha_{A}, \alpha_{B}, \alpha_{C}\right)$. In the region where $e_{A}$ is the bottleneck, $e_{A}\left(\alpha_{A}\right)$ is independent of $q$, and in the region where $q$ is the bottleneck $q\left(\alpha_{B}, \alpha_{C}\right)$ is independent of $e_{A}$.

The best-response function for firm $A$ is given by $0 A C D$, whereas the bestresponse function for quality is given by $0 A B$. Provided that both zero effort and zero content provision is ruled out, there will a continuum of Nash-equilibria along the efficiency locus $b_{A} e_{A}^{*}=q\left(e_{B}^{*}, e_{C}^{*}\right)$; in fig. 2 this is along the locus $0 A$. This is, in essence, identical to that of Vislie (1994). If the entire value of the output is shared among the firms, then reducing firm $A$ 's share of the value of total output shifts $e_{A}\left(\alpha_{A}\right)$ down, and $q\left(\alpha_{B}, \alpha_{C}\right)$ up. This is, however, not necessarily the case, since some of the value of the production may be allocated to end-users or the intermediary. 


\section{$3 \quad$ Implementing efficiency}

\subsection{Implementing the first-best effort levels}

In addition to being on the locus $b_{A} e_{A}^{*}=q\left(e_{B}^{*}, e_{C}^{*}\right)$, efficiency requires that $\alpha_{j}$ be set so that $e_{j}^{*}=\widetilde{e}_{j}$, where $e_{j}^{*}$ is defined by (7) and $\widetilde{e}_{j}$ is defined by $(11)$, for $j, k=B, C$ and $j \neq k$ :

$$
\alpha_{j}^{*}=\frac{b_{A}^{2} \varphi_{j} \varphi_{k}}{b_{A}^{2} \varphi_{B} \varphi_{C}+\varphi_{A}\left(\beta_{B}^{2} \varphi_{C}+\beta_{C}^{2} \varphi_{B}\right)}
$$

To ensure efficient effort by the platform provider, the following must be satisfied:

$$
\alpha_{A}^{*}=\frac{\varphi_{A}\left(\beta_{B}^{2} \varphi_{C}+\beta_{C}^{2} \varphi_{B}\right)}{b_{A}^{2} \varphi_{B} \varphi_{C}+\varphi_{A}\left(\beta_{B}^{2} \varphi_{C}+\beta_{C}^{2} \varphi_{B}\right)}
$$

Proposition 1 No simple linear sharing rule can implement the socially efficient outcome in a situation with complementary teams when there is competition on one side of the market.

With the sharing rule consisting of (12) and (13) budget balance is not ensured. Adding up the share received by firms $A, B$ and $C$ shows that $\sum_{i=A}^{C} \alpha_{i}>1$. This implies that in order to implement the efficient outcome with a simple linear sharing rule, the three firms must be allocated more than the total value of their joint output; that is, $\sum_{i=A}^{C} \alpha_{i} F(e)>F(e)$. Contrary to the complementary teams outcome in Vislie (1994) no efficient linear sharing rule exists due to content being provided by a team exerting substitutable efforts.

\subsubsection{Symmetric effort costs}

Assume that the content providers have identical (effort) cost functions $v_{j}\left(e_{j}\right)=$ $\varphi e_{j}^{2} / 2$ for $j=B, C$, and let $q\left(e_{B}, e_{C}\right)=\sum_{j} \beta_{j} e_{j}$. The (marginal) effort cost is identical for both firms, but the effort of each of the content providers has a different impact on content quality. The distribution network is assumed to have the following effort cost function: $v_{A}\left(e_{A}\right)=\varphi_{A} e_{A}^{2} / 2$. The solution for the socially efficient effort levels can be rewritten as:

$$
e_{j}^{*}=\frac{b_{A}^{2} \beta_{j} \varphi}{b_{A}^{2} \varphi^{2}+\varphi_{A} \varphi\left(\beta_{B}^{2}+\beta_{C}^{2}\right)}
$$


From (5) we find the corresponding $e_{A}^{*}$ :

$$
e_{A}^{*}=\frac{\varphi b_{A}\left(\beta_{B}^{2}+\beta_{C}^{2}\right)}{b_{A}^{2} \varphi^{2}+\varphi_{A} \varphi\left(\beta_{B}^{2}+\beta_{C}^{2}\right)}
$$

with the sharing rule to implement efficiency given by:

$$
\begin{aligned}
& \alpha_{j}^{*}=\frac{b_{A}^{2} \varphi^{2}}{b_{A}^{2} \varphi^{2}+\varphi_{A} \varphi\left(\beta_{B}^{2}+\beta_{C}^{2}\right)} \\
& \alpha_{A}^{*}=\frac{\varphi_{A} \varphi\left(\beta_{B}^{2}+\beta_{C}^{2}\right)}{b_{A}^{2} \varphi^{2}+\varphi_{A} \varphi\left(\beta_{B}^{2}+\beta_{C}^{2}\right)}
\end{aligned}
$$

Summing up (16) and (17), we find that the sharing rule which implements

efficient effort levels fails to ensure budget balance, since $\sum \alpha_{i}=1+\frac{b_{A}^{2} \varphi^{2}}{b_{A}^{2} \varphi^{2}+\varphi_{A} \varphi\left(\beta_{B}^{2}+\beta_{C}^{2}\right)}$ which is strictly larger than 1 .

\subsection{Implementing second-best effort}

The fact that there is competition in one of the market segments results in inability to utilise simple linear sharing rules to implement the first-best effort levels. Put differently, competition is not sustainable if one is restricted to linear sharing rules. The result above assumes that all three firms must be active in an equilibrium. Such a requirement can be due to regulatory and/or competition policy. One simple way around the implementation problem would be to set the following sharing rule: $\left\{\alpha_{A}=\alpha_{A}^{*}, \alpha_{j}=\alpha_{j}^{*}, \alpha_{k}^{*}=0\right\}$. Then we are essentially back in the model of Vislie (1994), and implementation of the socially efficient effort levels is possible by use of linear sharing rules. Another way is to maximise a restricted welfare function, with budget balance imposed directly on the maximisation problem. We will consider both these situations.

\subsubsection{Foreclosure}

If we ban one of the content providers from delivering added value to content quality by setting $\alpha_{k}^{*}=0$, the socially optimal effort and quality levels will be different to the levels defined by (7), (8) and (9). Define the level of optimal content quality with a single content provider as $q^{* *}$, and let the corresponding effort level for the 
content and platform providers be defined as $e_{j}^{* *}$ and $e_{A}^{* *}$. These effort and quality levels are given by:

$$
\begin{aligned}
e_{j}^{* *} & =\frac{b_{A}^{2} \beta_{j}}{b_{A}^{2} \varphi_{j}+\varphi_{A} \beta_{j}^{2}} \\
q^{* *} & =\frac{b_{A}^{2} \beta_{j}^{2}}{b_{A}^{2} \varphi_{j}+\varphi_{A} \beta_{j}^{2}} \\
e_{A}^{* *} & =\frac{b_{A} \beta_{j}^{2}}{b_{A}^{2} \varphi_{j}+\varphi_{A} \beta_{j}^{2}}
\end{aligned}
$$

Furthermore, define the difference $\Delta \equiv q^{*}-q^{* *}$, where $q^{*}$ is defined by (9). It is easily shown that $\Delta>0$. Thus, optimal quality is higher with two content providers. The reason for this is twofold. First, the cost of effort is convex, which implies that is more costly to produce the same effort level (and thereby quality) by a single firm. This tends towards a lower socially optimal level of (total) effort with a single content provider. Note, however, that the effort provided by the single remaining content provider, firm $j$, is in fact higher compared to the effort provided by firm $j$ when all firms are active. However, provided that the more productive content provider is chosen as the single provider the sum of effort exerted by firms $j$ and $k$ in the first-best case is strictly larger than the effort provided by the single firm in the second-best case. Second, the marginal effect on quality of effort plays a role. The larger the marginal effect of effort on quality is for the active content provider, all other things equal, the more likely is it that total effort is higher with two active content providers. For a given cost function, a low marginal productivity of effort implies that the content providers must compensate by increasing effort to ensure high content quality. This can be seen directly from (7).

Let us, without loss of generality, assume that $\beta_{j}>\beta_{k}$. It is reasonable to assume that if only one of the content providers is active, this will be the firm that provides the highest effort level (for a given sharing rule) as given by (11). If the content providers have identical cost functions (or $\varphi_{j} \leq \varphi_{k}$ ), then $e_{j}>e_{k}$ if $\beta_{j}>\beta_{k}$. In this case it is easily shown that $e_{j}^{*}+e_{k}^{*}>e_{j}^{* *}$. Even if this inequality is not satisfied, the level of quality is reduced with a single content provider when taking into account the marginal impact on content quality of effort by firms $B$ and 
$C$. Since the content quality, $q$, is lower this implies from (5) that the effort provided by the platform provider firm is lower than if all firms are being active.

\subsubsection{Budget balanced sharing rule}

In this section, we will derive the second-best solutions that satisfies the following (relaxed) budget balance constraint $\left(a_{A}+a_{B}+a_{C}\right)=\theta$, where $\theta \leq 1$. This is a sharing option that stakeholders that aims for maximum welfare can choose in the absence of a rule that implements first-best social efficiency; i.e., if (21) is not feasible. We will continue to assume that effort cost for the content provider is symmetric; i.e., that $v_{j}\left(e_{j}\right)=\varphi e_{j}^{2} / 2$ for $j=B, C$.

Maximise $W$ with respect to $\left(a_{A}, a_{B}, a_{C}\right)$, subject to the following set of constraints: i) $b_{A} e_{A}=q\left(e_{B}, e_{C}\right)$, ii) $e_{A}\left(a_{A}\right)=a_{A} b_{A} / \varphi_{A}$, iii) $e_{B}\left(a_{B}\right)=a_{B} \beta_{B} / \varphi$ and iv) $e_{C}\left(a_{C}\right)=a_{C} \beta_{C} / \varphi$. The objective function can, after incorporating these constraints, be rewritten as:

$$
\begin{aligned}
W= & \beta_{B}\left(a_{B} \beta_{B} / \varphi\right)+\beta_{C}\left(a_{C} \beta_{C} / \varphi\right)-\frac{\varphi_{A}}{2}\left(\left(\frac{a_{B} \beta_{B}^{2}+a_{C} \beta_{C}^{2}}{\varphi}\right) / b_{A}\right)^{2} \\
& -\frac{\varphi}{2}\left(\frac{a_{B} \beta_{B}}{\varphi}\right)^{2}-\frac{\varphi}{2}\left(\frac{a_{C} \beta_{C}}{\varphi}\right)^{2}
\end{aligned}
$$

Then incorporate the additional constraint:

$$
\left(a_{A}+a_{B}+a_{C}\right)=\theta
$$

which yields

$$
\begin{aligned}
\Theta= & a_{B} \beta_{B}^{2} / \varphi+a_{C} \beta_{C}^{2} / \varphi-\frac{\varphi_{A}}{2}\left(\left(\frac{a_{B} \beta_{B}^{2}+a_{C} \beta_{C}^{2}}{\varphi}\right) / b_{A}\right)^{2} \\
& -\frac{\left(a_{B} \beta_{B}\right)^{2}}{2 \varphi}-\frac{\left(a_{C} \beta_{C}\right)^{2}}{2 \varphi}-\lambda\left(a_{A}+a_{B}+a_{C}-\theta\right)
\end{aligned}
$$

The solution that maximises welfare in (18) is summarised in the following proposition:

Proposition 2 When the proposed sharing rule must comply with the restriction $a_{A}+a_{B}+a_{C}=\theta$, where $\theta$ represents the share of total output awarded to the three 
firms $A, B$ and $C$, then the following shares will be allocated to the firms:

$$
\begin{aligned}
\widehat{a}_{A} & =\frac{\varphi_{A}\left(\beta_{B}^{4}+\beta_{C}^{4}-2(1-\theta) \beta_{B}^{2} \beta_{C}^{2}\right)}{\varphi_{A}\left(\beta_{B}^{4}+\beta_{C}^{4}\right)+\varphi b_{A}^{2}\left(\beta_{B}^{2}+\beta_{C}^{2}\right)} \\
\widehat{a}_{B} & =\frac{b_{A}^{2} \beta_{B}^{2} \varphi+(1-\theta)\left(\beta_{B}^{2} \beta_{C}^{2} \varphi_{A}-b_{A}^{2} \beta_{C}^{2} \varphi-\beta_{C}^{4} \varphi_{A}\right)}{\varphi_{A}\left(\beta_{B}^{4}+\beta_{C}^{4}\right)+\varphi b_{A}^{2}\left(\beta_{B}^{2}+\beta_{C}^{2}\right)} \\
\widehat{a}_{C} & =\frac{b_{A}^{2} \beta_{C}^{2}+(1-\theta)\left(\beta_{B}^{2} \beta_{C}^{2} \varphi_{A}-b_{A}^{2} \beta_{B}^{2} \varphi-\beta_{B}^{4} \varphi_{A}\right)}{\varphi_{A}\left(\beta_{B}^{4}+\beta_{C}^{4}\right)+\varphi b_{A}^{2}\left(\beta_{B}^{2}+\beta_{C}^{2}\right)}
\end{aligned}
$$

Proof: See Appendix.

When comparing the restricted output shares with the sharing rule that implement the first-best effort levels we find the following:

$$
\begin{aligned}
& \alpha_{A}^{*}-\widehat{a}_{A}>0 \\
& \alpha_{B}^{*}-\widehat{a}_{B}>0 \text { if } b_{A}^{2} \varphi_{B} \varphi_{C}-\varphi_{A}\left(\beta_{B}^{2} \varphi_{C}-\beta_{C}^{2} \varphi_{B}\right)>0 \\
& \alpha_{C}^{*}-\widehat{a}_{C}>0 \text { if } b_{A}^{2} \varphi_{B} \varphi_{C}+\varphi_{A}\left(\beta_{B}^{2} \varphi_{C}-\beta_{C}^{2} \varphi_{B}\right)>0
\end{aligned}
$$

Based on (19) and (20) we observe the following:

Corollary 1 i) The more productive of the content providers get more relative to the less efficient partner in the second-best case (in the first-best case content providers received equal shares).

ii) The more productive content provider may earn a higher share than in the first-best case provided that the cost of effort for firm $A$ is high and the difference in productivity is sufficiently high.

iii) The platform provider always will earn less than in the first-best case.

A sufficient condition for $\alpha_{B}^{*}-\widehat{a}_{B}>0$ is $\beta_{B}<\beta_{C}$, but this is not sufficient to ensure that $\alpha_{C}^{*}-\widehat{a}_{C}<0$. The restricted sharing rule (19) will lead to a distortion in the second-best effort levels compared to first-best effort levels in the same direction as above. We find the second-best effort levels by using (19), (11) and (10), and 
they are given by:

$$
\begin{aligned}
& e_{A}=\frac{b_{A}\left(\beta_{B}^{4}+\beta_{C}^{4}\right)-2(1-\theta) b_{A} \beta_{B}^{2} \beta_{C}^{2}}{b_{A}^{2} \varphi\left(\beta_{B}^{2}+\beta_{C}^{2}\right)+\varphi_{A}\left(\beta_{B}^{4}+\beta_{C}^{4}\right)} \\
& e_{B}=\frac{b_{A}^{2} \beta_{B}^{3} \varphi-(1-\theta) \beta_{C}^{2} \beta_{B}\left(b_{A}^{2} \varphi-\varphi_{A}\left(\beta_{B}^{2}-\beta_{C}^{2}\right)\right)}{b_{A}^{2} \varphi^{2}\left(\beta_{B}^{2}+\beta_{C}^{2}\right)+\varphi_{A} \varphi\left(\beta_{B}^{4}+\beta_{C}^{4}\right)} \\
& e_{C}=\frac{b_{A}^{2} \beta_{C}^{3} \varphi-(1-\theta) \beta_{C} \beta_{B}^{2}\left(b_{A}^{2} \varphi+\varphi_{A}\left(\beta_{B}^{2}-\beta_{C}^{2}\right)\right)}{b_{A}^{2} \varphi^{2}\left(\beta_{B}^{2}+\beta_{C}^{2}\right)+\varphi_{A} \varphi\left(\beta_{B}^{4}+\beta_{C}^{4}\right)}
\end{aligned}
$$

Provided that $\theta<1$, which implies that some surplus is left to either the intermediary or the end-users, then the following is true: ${ }^{5}$

Corollary 2 i) Effort for firm $A$ is distorted downwards from a situation where $\theta=1$, since $\partial e_{A} / \partial \theta>0$.

ii) Effort for firms $B$ : $\partial e_{B} / \partial \theta>0$ if $\left(b_{A}^{2} \varphi-\varphi_{A}\left(\beta_{B}^{2}-\beta_{C}^{2}\right)\right)>0$, and

iii) Effort for firm $C$ : $\partial e_{C} / \partial \theta>0$ if $\left(b_{A}^{2} \varphi+\varphi_{A}\left(\beta_{B}^{2}-\beta_{C}^{2}\right)\right)>0$.

We see from Corollary 2 that when a larger share of the value of output that is allocated to the firms by increasing $\theta$ this results in an increase in the overall output in the market. ${ }^{6}$ We also observe that the content providers' effort levels may change either way depending on relative productivity parameters. The less productive of the content providers will always increase his effort as $\theta$ increases, and the more efficient content provider may increase his effort (but by a smaller magnitude) if the difference in content providers' productivity is not too large and that the effort cost for firm $A$ is not too large. We see that if $\beta_{C}>\beta_{B}$, then $\partial e_{B} / \partial \theta<0$ and $\partial e_{C} / \partial \theta<0$ if $\varphi_{A}$ is small and $\left(\beta_{C}-\beta_{B}\right)$ not too positive. If $\varphi_{A}$ is large and/or $\left(\beta_{C}-\beta_{B}\right)$ is large (and positive), then $\partial e_{C} / \partial \theta>0$.

\footnotetext{
${ }^{5} \mathrm{~A}$ sufficient but not necessary condition for the effort of firm $B$ to be increasing in $\theta$ is $\beta_{C}>$ $\beta_{B}$, which is equivalent to the condition that ensures $\alpha_{B}^{*}-\widehat{a}_{B}>0$. A sufficient but not necessary condition for the effort of firm $C$ to be increasing is $\beta_{B}>\beta_{C}$, which is equivalent to ensuring that $\alpha_{C}^{*}-\widehat{a}_{C}>0$.

${ }^{6}$ We observe that $e_{A}$ is increasing in $\theta$, and since efficiency requires $b_{A} e_{A}=\beta_{B} e_{B}+\beta_{C} e_{C}$, then the effort by content providers must also increase.
} 


\subsection{Solving the implementation problem}

In this section I will propose a sharing rules to attempt to correct for the inability of a simple linear sharing rule to implement efficiency and budget balance. ${ }^{7}$ To be more precise, we do not require budget balance but rather that $\sum_{i=A}^{C} \alpha_{i} F(e) \leq F(e)$. We assume that the platform provider is the residual claimant, but not necessarily of the total value of production. The share of the value of output allocated to the three firms depends on who sets the tariff, and this may be either the platform, the intermediary or end-users.

Proposition 3 The following sharing rule implements the socially efficient effort vector $e^{*}$ and ensures $b_{A} e_{A}^{*}=q^{*}$ :

$$
\begin{aligned}
\alpha_{j} & =\left\{\begin{array}{cc}
a_{j} & \text { if } x \geq F\left(e^{*}\right) \equiv \min \left\{b_{A} e_{A}^{*}, \beta_{B} e_{B}^{*}+\beta_{C} e_{C}^{*}\right\} \\
0 & \text { if } x<F\left(e^{*}\right) \equiv \min \left\{b_{A} e_{A}^{*}, \beta_{B} e_{B}^{*}+\beta_{C} e_{C}^{*}\right\}
\end{array}\right. \\
\alpha_{A} & =\theta-a_{B}-a_{C}
\end{aligned}
$$

This particular sharing rule can be given different interpretations depending on the purchasing arrangements, and will depend both on who bundles and sells the product (i.e., who proposes the sharing rule), and how the bargaining power is allocated among the economic agents in the game (i.e., who determines $\theta$ ). Another way of interpreting the sharing rule is that either the intermediary (or end-users) device a contract that specifies how much of the total output should be awarded to the content providers and how much the intermediary (or end-users) retains. We assume that the player that proposes the sharing rule can commit to this rule. As we will see below, this may not always be the case. In particular, if the player that proposes the sharing rule is a stakeholder there may be a commitment problem.

Let us see why this rule implements the socially efficient outcome. ${ }^{8}$ We know that $e^{*}$ defines the (unique) efficient output and is the effort vector that maximises (4). This yields the socially optimal quality level, $q^{*}$, defined by (9). To allow for the

\footnotetext{
${ }^{7}$ Legros and Matthews (1993) provide necessary and sufficient conditions for efficiency in teams in a generalised setting.

${ }^{8}$ The sharing rule is similar to that proposed by Holmstrom (1982).
} 
possibility that the intermediary firm or end-users capture some of the surplus, we let $\theta \in\left(a_{B}+a_{C}, 1\right]$. The total value of the partnership output is, by construction, divided among the (productive) partnership members if $\theta=1$. This case may be seen as the outcome with perfect price discrimination. If, on the other hand, $\theta=a_{B}+a_{C}$ the intermediary firm (or end-users) takes all the residual profit. This leaves the platform provider with a negative profit for all positive effort levels, which will induce zero effort by the platform provider. To avoid this we will assume that firm $A$ earns a strictly positive share of the value of total output. The proposed sharing rule implies that the distribution network is residual claimant of the value of production if $\theta=1$. If $\theta=1$ this implies that neither the intermediary nor end-users gain positive surplus, and can be interpreted as the case where both the market for intermediaries is highly competitive and all bargaining power rests with the platform provider. Thus, $\theta$ can be seen as a proxy for both competition in the market for intermediaries and a proxy for bargaining power.

The payoffs can be rewritten as follows: ${ }^{9}$

$$
\pi_{j}= \begin{cases}a_{j} x-\varphi_{j} e_{j}^{2} / 2 & \text { if } x \geq F\left(e^{*}\right) \equiv \min \left\{b_{A} e_{A}^{*}, \beta_{B} e_{B}^{*}+\beta_{C} e_{C}^{*}\right\} \\ -\varphi_{j} e_{j}^{2} / 2 & \text { if } x<F\left(e^{*}\right) \equiv \min \left\{b_{A} e_{A}^{*}, \beta_{B} e_{B}^{*}+\beta_{C} e_{C}^{*}\right\}\end{cases}
$$

and

$$
\pi_{A}=\left\{\begin{array}{cc}
\left(\theta-a_{B}-a_{C}\right) x-\varphi_{A} e_{A}^{2} / 2 & \text { if } x \geq F\left(e^{*}\right) \equiv \min \left\{b_{A} e_{A}^{*}, \beta_{B} e_{B}^{*}+\beta_{C} e_{C}^{*}\right\} \\
\theta x-\varphi_{A} e_{A}^{2} / 2 & \text { if } x<F\left(e^{*}\right) \equiv \min \left\{b_{A} e_{A}^{*}, \beta_{B} e_{B}^{*}+\beta_{C} e_{C}^{*}\right\}
\end{array}\right.
$$

where $x$ is defined by (1). From (22) it is clear that no single content provider has an incentive to deviate from the socially optimal effort level $e_{j}^{*}$, provided that firm $A$ chooses $e_{A}=e_{A}^{*}$, and provided that the game is played only once. If either content provider deviates from the socially optimal effort levels, they will earn negative profits. Firm $A$, on the other hand, may have an incentive to deviate when $\left(e_{B}^{*}, e_{C}^{*}\right)$. By choosing a lower effort than $e_{A}^{*}$, we are in the region where distribution effort

\footnotetext{
${ }^{9}$ The pay-off functions will naturally be affected by which factor is the bottleneck.
} 
is the bottleneck; $b_{A} e_{A}<q^{*}\left(e_{B}^{*}, e_{C}^{*}\right)$. The profit for firm $A$ depends here only on its own effort $e_{A}$. In the same region, it is easily seen that firm $j$ benefits from an increase in $e_{A}$ and a reduction in $e_{j}$. The region in which either input is a bottleneck is endogenous and will depend on the sharing rule. If the sharing rule is such that the content providers get a small share of the value of the output, this will result in a low effort and consequently in low content quality $q$. If the sharing rule is defined by (21) and provided that firms $B$ and $C$ choose $e_{B}^{*}$ and $e_{C}^{*}$, firm $A$ will receive a net profit provided that $\hat{e}_{A}$ satisfies the following: $\pi_{A}=\theta b_{A} \hat{e}_{A}-\varphi_{A} \hat{e}_{A}^{2} / 2>0$. Firm $A$ will only have an incentive to deviate from the socially optimal effort level if $\pi_{A}^{*}\left(e_{A}^{*}, e_{B}^{*}, e_{C}^{*}\right)<\theta b_{A} \hat{e}_{A}-\varphi_{A} \hat{e}_{A}^{2} / 2$, assuming socially optimal effort levels $\left(e_{B}^{*}, e_{C}^{*}\right)$ by the content providers.

A deviation from the socially optimal level must be such that $\hat{e}_{A}<e_{A}^{*}$. Any deviation such that $\hat{e}_{A}>e_{A}^{*}$ implies that content quality is the bottleneck factor, and firm $A$ 's profit is decreasing in its own effort in this region. If the sharing rule is such that $1 \geq \theta \geq \alpha_{A}^{*}$, then $\hat{e}_{A}=e_{A}^{*}$. If $\left(a_{B}+a_{C}\right)<\theta<\alpha_{A}^{*}$, the distribution network is the bottleneck and the maximisation problem of firm $A$ yields $\hat{e}_{A}=\theta b_{A} / \varphi_{A}$. This yields a profit level of:

$$
\pi_{A}\left(\hat{e}_{A}, e_{B}^{*}, e_{C}^{*}\right)=\frac{\left(\theta b_{A}\right)^{2}}{2 \varphi_{A}}>0
$$

and the profit in the socially optimal outcome is, which we will assume is strictly positive (a sufficient condition for this is that more than $50 \%$ of the value of total output is shared among the firms; $\theta>1 / 2$ ):

$$
=\frac{\pi_{A}^{*}\left(e_{A}^{*}, e_{B}^{*}, e_{C}^{*}\right)}{2\left(b_{A}^{2} \varphi^{2}+\varphi_{A} \varphi\left(\beta_{B}^{2}+\beta_{C}^{2}\right)\right)^{2}}=0
$$

The difference in profit is then:

$$
\begin{aligned}
& \pi_{A}^{*}\left(e_{A}^{*}, e_{B}^{*}, e_{C}^{*}\right)-\pi_{A}\left(\hat{e}_{A}, e_{B}^{*}, e_{C}^{*}\right) \\
= & -\frac{b_{A}^{2}\left(\theta b_{A}^{2} \varphi^{2}-(1-\theta) \varphi_{A} \varphi\left(\beta_{C}^{2}+\beta_{B}^{2}\right)\right)^{2}}{2 \varphi_{A}\left(b_{A}^{2} \varphi_{B} \varphi_{C}+\beta_{B}^{2} \varphi_{A} \varphi_{C}+\beta_{C}^{2} \varphi_{A} \varphi_{B}\right)^{2}}<0
\end{aligned}
$$

This shows that the distribution network will earn higher profit when deviating even when $a_{B}=a_{C}=0$, provided that $\left(e_{B}^{*}, e_{C}^{*}\right)$. Naturally, to induce $\left(e_{B}^{*}, e_{C}^{*}\right)$ it is 
necessary to leave the content providers with a positive share of output, but this will imply that the profit for firm $A$ with $\left(e_{A}^{*}, e_{B}^{*}, e_{C}^{*}\right)$ is even smaller. This means that the profit difference in (25) becomes more negative.

The content providers will earn negative profits (zero profits if $e_{j, k}=0$ ) if they choose a lower effort than $\left(e_{B}^{*}, e_{C}^{*}\right)$ even if $e_{A}=e_{A}^{*}$, since the content quality is the bottleneck in such a case. This would imply that $e_{j, k}=0$. A positive level of effort would yield negative profits. Thus, in the event of a deviation in effort levels this would imply zero effort (and zero profit). The distribution network may still deviate from $e_{A}^{*}$ profitably, for a given set of positive $\left(e_{B}, e_{C}\right)$ since $A$ may capture some surplus even with $e_{A}<e_{A}^{*}$. This incentive will be foreseen by the content providers, and they will choose zero effort, which will result in zero production and negative profit for firm $A$. This implies that the only Nash equilibrium in effort for the proposed sharing rule is $\left(e_{A}^{*}, e_{B}^{*}, e_{C}^{*}\right)$. In addition, budget balance may be achieved by setting $\theta=1$.

We assumed initially that the sharing rule can be committed to. There may, however, be a problem with lack of commitment to the proposed sharing rule, depending on who proposes the sharing rule. Firm $A$ is a stakeholder in the game, and may have an incentive to renegotiate if $x<F\left(e^{*}\right)$, to avoid an outcome with zero production. In other words, the punishment of a zero share of the output may not be credible.

The platform sets the sharing rule One interpretation of the sharing rule (21) can be that the platform sets the rule to maximise its own profit. It is straightforward to check that $\pi_{A}$ is increasing in $\theta$ which implies that the platform provider will choose to retain the residual value of output if $\theta$ is a decision variable for firm $A$ by choosing $\theta=1$ to maximise its own profit. The platform will bypass the intermediary provided that commitment is possible. It is, however, possible that the size of $\theta$ is determined to be strictly lower than 1, e.g., through regulatory intervention, or due to distribution of bargaining power. ${ }^{10}$

The timing of the game is as follows: First a decision on $\theta$ is made. Then, the

\footnotetext{
${ }^{10}$ The bargaining process is not investigated in the present paper.
} 
decision maker decides on how to share the value of output (given the decision on $\theta$ ). Finally, firms $i=A, B, C$ choose their effort levels. Below, we will also consider the case in which commitment is not possible. Then, renegotiation of the sharing rule will take place if (21) does not provide sufficient remuneration for firms. ${ }^{11}$ Initially, it is assumed that the game is a one-shot game without the option of renegotiation.

If we assume that no renegotiation is possible then a sharing rule that implements the socially optimal effort vector will be proposed if the profit for firm $A$ in the firstbest optimum is higher than in the second-best optimum. We need to compare the platform's profit when socially optimal effort levels are implemented with the case where the platform maximises its profits with respect to $\left(a_{B}, a_{C}\right)$, subject to the best-response functions of the content providers.

Lemma 1 To ensure implementation of the efficient sharing rule (21) the profit for firm $A$ with the efficient effort vector, defined as $\pi_{A}^{*}$, must be higher than in the best alternative, defined as $\pi_{A}^{\prime}$.

The platform provider can alternatively propose to implement a different sharing rule. It can be shown that firm $A$ 's profit is decreasing in $\left(a_{B}, a_{C}\right)$, so firm $A$ will wish to set the sharing parameters to firms $B$ and $C$ as low as possible, but the content providers must be allocated a part of the value of output to induce positive effort levels. In the following I will maintain the assumption that the effort costs of the content providers are symmetric; $\varphi_{B}=\varphi_{B}=\varphi$.

Maximising $\pi_{A}=\left(\theta-a_{B}-a_{C}\right) b_{A} e_{A}-\frac{\varphi_{A}}{2}\left(e_{A}\right)^{2}$ with respect to $e_{A}$ yields the profit maximising output level:

$$
e_{A}^{\prime} \equiv \frac{\left(\theta-a_{B}-a_{C}\right) b_{A}}{\varphi_{A}}
$$

By using the fact that efficient production due to strict complementarity implies

\footnotetext{
${ }^{11}$ In order to be able to implement the first-best outcome, two (incentive) conditions must be satisfied: 1) The decision maker must earn higher profit in the first-best case, and 2) the (productive) firms must earn at least the same level of profit as in the alternative outcome (the renegotiation case).
} 
$b_{A} e_{A}=q\left(e_{B}, e_{C}\right)$ where $e_{B}\left(a_{B}\right)=a_{B} \beta_{B} / \varphi$ and $e_{C}\left(a_{C}\right)=a_{C} \beta_{C} / \varphi$, we find:

$$
\frac{a_{j} \beta_{j}^{2}+a_{k} \beta_{k}^{2}}{\varphi}=\frac{\left(\theta-a_{j}-a_{k}\right) b_{A}^{2}}{\varphi_{A}}
$$

Equation (26) defines a combination of $\left(a_{j}, a_{k}\right)$ that implements the profit maximising output level:

$$
a_{j}=\frac{\theta \varphi b_{A}^{2}-a_{k}\left(\varphi b_{A}^{2}+\beta_{k}^{2} \varphi_{A}\right)}{\varphi b_{A}^{2}+\beta_{j}^{2} \varphi_{A}}
$$

and can be shown that the platform provider can, by choosing the most productive content provider as the only provider, minimise transfers and still produce the profit maximising level of output:

Lemma 2 (Alternative sharing rule) If the platform provider chooses an alternative sharing rule to (21), then only the most productive content provider will be offered a positive share of the value of output. The share awarded to the content provider is defined below by (28).

Assume without loss of generality that $\beta_{j}>\beta_{k}$. Then, firm $j$ will be chosen to provide content, and the higher $\beta_{j}$ is the lower share of output is awarded to the content provider. This may seem somewhat counterintuitive, but the reason for this is simply that the more productive an agent is the higher is his effort for a given share of the value of output. Thus, a certain quality level for content provision can be achieved either by the less productive agent by awarding a higher share of the value of output, or it can be achieved at lower cost (for the agent proposing the contract) by the more productive agent. If we assume that firm $j$ is chosen, the share of the value of output to $j$ is

$$
a_{j}^{\prime}=\frac{\theta \varphi b_{A}^{2}}{\varphi b_{A}^{2}+\beta_{j}^{2} \varphi_{A}}
$$

which leaves the following share to firm $A$ :

$$
\theta-a_{j}^{\prime}=\frac{\theta \beta_{j}^{2} \varphi_{A}}{\varphi b_{A}^{2}+\beta_{j}^{2} \varphi_{A}}
$$

By using (5) we find the corresponding effort for firm $A$ :

$$
e_{A}^{\prime}=\frac{\theta \beta_{j}^{2} b_{A}}{\left(\varphi b_{A}^{2}+\varphi_{A} \beta_{j}^{2}\right)}
$$


By examining the profit for firm $A$ in the case where first-best effort levels are implemented with sharing rule (21), we will be able to ascertain whether firm $A$ will want to implement this rule. In order to make the comparison we need to determine the share of the value of output that content providers require to satisfy the limited liability constraint (zero profit constraint). By using (22) we find

$$
\pi_{j}^{*}=a_{j} q^{*}-\varphi\left(e_{j}^{*}\right)^{2} / 2
$$

Inserting for socially optimal content quality (9), effort for firm $j$ (7), and setting $\pi_{j}^{*}=0$, we find the lowest share $a_{j}$ that firm $j$ will accept. Let us define this as $\widetilde{a}_{j}$, and let $\widetilde{a}_{j}$ for $j=B, C$ be given as:

$$
\widetilde{a}_{j}=\frac{\beta_{j}^{2} \varphi b_{A}^{2}}{2\left(\beta_{j}^{2}+\beta_{k}^{2}\right)\left(\varphi b_{A}^{2}+\varphi_{A}\left(\beta_{j}^{2}+\beta_{k}^{2}\right)\right)}
$$

where $\widetilde{a}_{j}+\widetilde{a}_{k}<1 / 2$. The share to firm $A$ is given by:

$$
\theta-\left(\widetilde{a}_{j}+\widetilde{a}_{k}\right)=\frac{\left((2 \theta-1) \varphi b_{A}^{2}+2 \theta \varphi_{A}\left(\beta_{j}^{2}+\beta_{k}^{2}\right)\right)}{2\left(\varphi b_{A}^{2}+\varphi_{A}\left(\beta_{j}^{2}+\beta_{k}^{2}\right)\right)}
$$

By comparing (32) and (29) we find that the former is strictly larger than the latter, and consequently the platform provider obtains a larger share of the value of output when the efficient effort vector is implemented provided that $\theta \geq 1 / 2$. This condition must be met to ensure non-negative profit for firm $A$ when the efficient effort vector is implemented, and is assumed to be satisfied throughout. Comparing (15) with (30), we find that effort is higher for firm $A$ when the first-best effort levels are implemented.

Lemma 3 If the platform chooses the efficient sharing rule, (21), a positive share of the value of output will be awarded to firms $j=B, C$, defined by (31).

From Lemmas 1-3 we have the following main result:

Proposition 4 i) If the entire value of output is shared among the three productive firms, $A, B$ and $C$, then firm $A$ will want to implement the efficient sharing rule given by (21). 
ii) If some of the surplus is awarded to economic agents other than $A, B$ or $C$ for some unspecified reason, then (21) is only chosen by firm A provided that the following inequality holds:

$$
\frac{2 \theta-1}{\theta^{2}}>\frac{\beta_{j}^{4} \varphi_{A}\left(\varphi b_{A}^{2}+\varphi_{A}\left(\beta_{j}^{2}+\beta_{k}^{2}\right)\right)}{\left(\beta_{j}^{2}+\beta_{k}^{2}\right)\left(\varphi b_{A}^{2}+\varphi_{A} \beta_{j}^{2}\right)^{2}}
$$

When comparing profit levels for firm $A$ it is revealed that $\pi_{A}^{*}-\pi_{A}^{\prime}>0$ if $\theta=1$. Here, $\pi_{A}^{*}$ is the profit level for $A$ with a share to content firms $j$ and $k$ given by $\left(\widetilde{a}_{j}, \widetilde{a}_{k}\right)$ and with efficient effort levels, whereas $\pi_{A}^{\prime}$ is the profit level associated with the outcome in the alternative sharing rule (28) with only a single content provider. Consequently, setting $\theta=1$ ensures that the platform provider will choose a sharing rule to implement the first-best outcome. ${ }^{12}$ The reason for this seems to be due to the fact that the implementation of the first-best effort levels is less costly than in the alternative solution. This is partly due to the fact that a single provider is chosen in the alternative case and is induced to provide excessive effort, since $e_{j}^{*}-e_{j}^{\prime}<0$, which combined with a convex effort cost necessitates a higher transfer to the content provider. However, if $\theta \in[0.5,1)$, i.e., if some of the value of production must be allocated to the intermediary or to end-users, the inequality (33) must be satisfied to ensure implementation of the first-best effort vector.

This inequality is not trivially satisfied for all permissible parameter combinations. Hence, for some combinations of parameter values the first-best outcome will not be implemented when the platform provider decides the sharing rule and if some of the value of production must be left to end-users (i.e., if $\theta<1$ ). This is summarised this in the following corollary:

Corollary 3 The first-best efficient outcome will not be implemented if (33) is violated. This condition will be violated when the productivity parameter of the most productive content provider becomes large, the productivity of the less productive firm becomes low, and when the platform provider is unable to capture a sufficiently large share of the surplus (in particular, if $\theta$ is relatively small and close to $1 / 2$.

\footnotetext{
${ }^{12}$ The condition $\theta=1$ is, as we will see below, not sufficient in the case when renegotiation is possible.
} 
The content providers will earn zero profit in the first-best scenario (by assumption) regardless the level of $\theta$, which is less than in the alternative scenario since $\pi_{j}^{\prime}>0$. They are consequently worse off if the platform provider can commit to the first-best scenario. ${ }^{13}$

End-users set the sharing rule In this setting, we assume that the endusers bypass the intermediary and purchases directly from the firms. The end-users cannot observe the individual components of the product, but this is not necessary as we have already seen that the sharing rule (21) implements the first-best effort levels. The end-users simply propose a sharing rule that allocates part of the surplus from trade to the three firms, and set $\theta$ to maximise consumers' surplus. The game is a one-shot game. The total value of production is here given as $F\left(e_{A}, q\left(e_{B}, e_{C}\right)\right)$. Consumers' surplus is decreasing in $\theta$, and will be zero if $\theta=1$, and is given by:

$$
C S\left(e_{A}, e_{B}, e_{C}\right)=(1-\theta) F\left(e_{A}, q\left(e_{B}, e_{C}\right)\right)
$$

The end-users must ensure that the sharing rule specifies shares to the three firms such that they will participate voluntarily (i.e., that profits are non-negative). We have seen that $\theta \geq 1 / 2$ is a sufficient condition for satisfying the constraint for the platform provider. A necessary condition to ensure non-negative profits for firm $A$ is the following:

$$
\theta \geq \frac{\varphi_{A}\left(\beta_{B}^{2}+\beta_{C}^{2}\right)}{2\left(\varphi b_{A}^{2}+\varphi_{A}\left(\beta_{B}^{2}+\beta_{C}^{2}\right)\right)} \equiv \theta^{*}
$$

By choosing $a_{j}=\widetilde{a}_{j}$ for $j=B, C$, where $\widetilde{a}_{j}$ is defined by (31) and $\theta=\theta^{*}<1 / 2$, end-users ensure that profits for all productive firms are non-negative. This yields the highest end-users' surplus in the first-best effort case, while at the same time ensuring voluntary participation by all three firms. If a sharing rule that implements efficiency is chosen, the following surplus is allocated to end-users:

$$
C S^{*}=\frac{\left(\varphi b_{A}^{2}+2 \varphi_{A}\left(\beta_{j}^{2}+\beta_{k}^{2}\right)\right)\left(\beta_{j}^{2}+\beta_{k}^{2}\right) b_{A}^{2}}{4\left(\varphi b_{A}^{2}+\varphi_{A} \beta_{j}^{2}+\varphi_{A} \beta_{k}^{2}\right)^{2}}
$$

\footnotetext{
${ }^{13}$ The fact that the content providers will earn higher profit with the alternative sharing rule implies that there may be commitment problems. This will be investigated below.
} 
If end-users choose an alternative sharing rule to (21) they will face a tradeoff since increasing the share to the productive firms will result in a direct loss to end-users, but it also increases the total output. Maximising (34) with respect to $\theta$ yields:

$$
\theta^{c s}=\frac{a_{j}+a_{k}+1}{2}>\frac{1}{2}
$$

Furthermore, efficiency in production requires that (5) is satisfied. Combining this with (37) implies that any combination of $\left(a_{j}, a_{k}\right)$ satisfying the following ensures an outcome that maximises end-users' surplus:

$$
\frac{b_{A}^{2}\left(1-a_{j}-a_{k}\right)}{2 \varphi_{A}}=\frac{a_{j} \beta_{j}^{2}+a_{k} \beta_{k}^{2}}{\varphi}
$$

or rewritten:

$$
a_{j}=\frac{\varphi b_{A}^{2}-a_{k}\left(\varphi b_{A}^{2}+2 \varphi_{A} \beta_{k}^{2}\right)}{\varphi b_{A}^{2}+2 \varphi_{A} \beta_{j}^{2}}
$$

Along the same lines as the argument in relation to Lemma 2, it can easily be shown that the lowest transfer to content providers that conforms with (38) is to choose only the most productive of the content providers. Consequently, if $\beta_{j}>\beta_{k}$ then firm $j$ will be the single active content provider. The surplus for the end-users will in this case be given by:

$$
C S^{\prime}=\frac{\varphi_{A} \beta_{j}^{4} b_{A}^{2}}{\left(\varphi b_{A}^{2}+2 \varphi_{A} \beta_{j}^{2}\right)^{2}}
$$

It can easily be shown that $C S^{*}>C S^{\prime}$, which implies that end-users will if possible always choose the sharing rule that implements social efficiency.

The intermediary sets the sharing rule In the cases where either the platform provider or the end-users cannot commit to a sharing rule that implements efficiency, the use of a market intermediary may be beneficial. If we consider a competitive market for intermediaries, then the intermediary firm will earn zero profit. Assuming that the marginal cost of the intermediary is normalised to zero, but allowing for a fixed cost $F$ for setting up the intermediary with $F \geq 0$, the value of output is shared among the active firms and end-users but with some concessions made for the recovery of the fixed cost (this will imply that $\theta$ cannot be 1 unless 
fixed costs are zero). The intermediary will be indifferent between the different outcomes, in which case we assume that he will and can commit to the sharing rule (21) that implements the efficient outcome characterised by (7), (8) and (5). By setting $\theta \geq \theta^{*}$ and $a_{j, k}=\widetilde{a}_{j, k}$ the intermediary ensures non-negative profits for all three active firms. ${ }^{14}$ There is a continuum of equilibria that supports efficiency, and the choice of allocation is in part dictated by who determines the size of $\theta$. As we have seen above, the platform provider would determine a $\theta=1$ whereas the end-users would set $\theta=\theta^{c s}$, where $\theta^{c s}$ is defined by (37) which is strictly less than 1 .

Provided that the inequality (33) is violated, then the platform provider will not choose the sharing rule that implements first-best effort. For certain parameter values (see Corollary 3) the intermediary may add value by allowing the implementation of the first-best outcome. The value of the intermediary can then be said to be the difference in welfare in the two cases (the first-best and the alternative outcomes) less the fixed cost of the intermediary. We will investigate this below.

\subsubsection{Welfare comparison}

Let us compare welfare in the case where the socially efficient solution is implemented with the alternative outcome. This will give us a measurement for the value of the intermediary. The first case, with sharing rule (21), which yields the sharing vector $\left(\widetilde{a}_{j}, \widetilde{a}_{k}, \widetilde{a}_{A}\right)$ and ensures both budget balance and first-best efficiency, and the second case where the platform provider uses the sharing rule (28) in which a single content provider is active (i.e., only the most efficient content provider is active). Let $\beta_{j}>\beta_{k}$, which implies that content provider $j$ will be active in the second case.

We know that the welfare in the first-best scenario is given by:

$$
W\left(e^{*}\right) \equiv \frac{b_{A}^{2} \varphi\left(\beta_{j}^{2}+\beta_{k}^{2}\right)}{2\left(b_{A}^{2} \varphi^{2}+\varphi_{A} \varphi\left(\beta_{j}^{2}+\beta_{k}^{2}\right)\right)}=F\left(e_{A}^{*}, q\left(e_{B}^{*}, e_{C}^{*}\right)\right) / 2>0
$$

The welfare level with only one content provider active is:

$$
W\left(e_{A}^{\prime}, e_{j}^{\prime}\right)=\frac{(2-\theta) \theta b_{A}^{2} \beta_{j}^{2}}{2\left(\varphi b_{A}^{2}+\varphi_{A} \beta_{j}^{2}\right)}=(2-\theta) F\left(e_{A}^{\prime}, q\left(e_{j}^{\prime}, e_{k}=0\right)\right) / 2>0
$$

\footnotetext{
${ }^{14}$ Note that the necessary condition on $\theta$ is reported in (35).
} 
Comparing (41) and (42) it is easily shown that welfare is strictly higher when all three firms are active for all permissible values for $\theta$ (this is, naturally, so by definition of the socially optimal effort levels). The difference between $W\left(e^{*}\right)$ and $W\left(e_{A}^{\prime}, e_{j}^{\prime}\right)$ shows how high the added value of the intermediary is exclusive of fixed costs and is given by:

$$
\begin{aligned}
& W\left(e^{*}\right)-W\left(e_{A}^{\prime}, e_{j}^{\prime}\right) \equiv \gamma \\
= & \frac{b_{A}^{2}\left(\varphi b_{A}^{2}\left(\beta_{j}^{2}\left(1-2 \theta+\theta^{2}\right)+\beta_{k}^{2}\right)+\varphi_{A} \beta_{j}^{2}\left(1-2 \theta+\theta^{2}\right)\left(\beta_{j}^{2}+\beta_{k}^{2}\right)\right)}{2\left(\varphi b_{A}^{2}+\varphi_{A}\left(\beta_{j}^{2}+\beta_{k}^{2}\right)\right)\left(\varphi b_{A}^{2}+\varphi_{A} \beta_{j}^{2}\right)}
\end{aligned}
$$

We immediately have the following result:

Proposition 5 i) If consumers cannot purchase the product directly and the platform provider has no incentive to implement the first-best allocation, then an intermediary firm is welfare improving if the following holds: $\gamma \geq F$.

ii) For an intermediary firm to appear as a distribution channel in equilibrium we also require that no other market structures dominates the market structure with the intermediary.

If the expression (43), which is defined as $\gamma$, is larger than the fixed cost $F$ of the intermediary, then it implies that the presence of an intermediary firm adds value to the market when the platform provider will not choose a sharing rule that implements the first-best effort levels (see corollary 3) and provided that end-users cannot purchase directly from the firms. If, however, $F$ is larger than (43) this implies that social welfare is higher with the alternative outcome and that the intermediary generates no added value.

\subsection{Commitment problems}

In this section we will investigate how the sharing rule must be adjusted when renegotiation is possible. I will only investigate the potential commitment problem in the case where the platform decides on the sharing rule. The platform cannot necessarily commit to a sharing rule that imposes negative transfers on the content providers, since the platform may have incentives to renegotiate to avoid a zero or 
negative profit level. There are now two conditions that must be satisfied to ensure that commitment is feasible:

Lemma 1' To ensure implementability of the efficient sharing rule (21) the profit for firm $A$ and firm $j$, for $j=B, C$, with the efficient effort vector must be higher than the alternative level of profit; i) $\pi_{A}^{*} \geq \pi_{A}^{\prime}$ and ii) $\pi_{j}^{*} \geq \pi_{j}^{\prime}$.

If the platform provider cannot commit to the sharing rule that implements the socially efficient effort vector, then an alternative sharing rule will be implemented since the platform provider will benefit from renegotiating the sharing rule in the event of a zero output. Since $\partial \pi_{A} / \partial a_{j}<0$ firm $A$ will set the sharing parameters to firms $B$ and $C$ as low as possible, but firm $A$ needs to take into account the response of firm $j$ to changes in the sharing rule. We have seen in section 3.3 that (27) defines the combination of $\left(a_{j}, a_{k}\right)$ that implements the profit maximising output level. The platform provider can, by choosing the most productive content provider as the only provider, minimise transfers and still produce the profit maximising level of output:

Lemma 2' If the platform provider cannot commit to the sharing rule that implements first-best efficiency, (21), then only the most productive content provider will be offered a positive share of the value of output. The share awarded to the content provider is identical to the alternative sharing rule discussed above and is defined by (28).

By examining the profit for firms $A, B$ and $C$ in the case where first-best effort levels are implemented with sharing rule (21), we will be able to ascertain whether firm $A$ can commit to this rule. By using (22) we find

$$
\pi_{j}^{*}=a_{j} q^{*}-\varphi\left(e_{j}^{*}\right)^{2} / 2
$$

Inserting for socially optimal content quality (9), effort for firm $j$ (7), and setting $\pi_{j}^{*}=\pi_{j}^{\prime}$, we find the lowest share $a_{j}$ that firm $j$ will accept if the first-best effort level is chosen. This share is defined as $\bar{a}_{j}$, where $\bar{a}_{j}>\widetilde{a}_{j}$ and where $\widetilde{a}_{j}$ is defined by (31):

$$
\bar{a}_{j}=\widetilde{a}_{j}+\frac{\theta^{2} \varphi b_{A}^{2} \beta_{j}^{2}\left(\varphi b_{A}^{2}+\varphi_{A}\left(\beta_{j}^{2}+\beta_{k}^{2}\right)\right)}{2\left(\beta_{j}^{2}+\beta_{k}^{2}\right)\left(\varphi b_{A}^{2}+\varphi_{A} \beta_{j}^{2}\right)^{2}}
$$


The loss imposed on the platform provider in order to satisfy the (incentive) constraint is given by:

$$
\Delta^{*}=\frac{\theta^{2} b_{A}^{4} \varphi\left(\varphi^{2} b_{A}^{4}\left(\beta_{j}^{2}+\beta_{k}^{2}\right)+\varphi_{A}^{2} \beta_{j}^{2} \beta_{k}^{2}\left(\beta_{k}^{2}+\beta_{j}^{2}\right)+4 \varphi b_{A}^{2} \varphi_{A} \beta_{j}^{2} \beta_{k}^{2}\right)}{2\left(\varphi b_{A}^{2}+\varphi_{A} \beta_{j}^{2}\right)^{2}\left(\varphi b_{A}^{2}+\varphi_{A} \beta_{k}^{2}\right)^{2}}>0
$$

Lemma 3' If the platform provider can commit to the efficient sharing rule, (21), he will award a positive share of the value of output to firms $j=B, C$, defined by (44). The platform provider will obtain a profit level given by $\pi_{A}^{* *} \equiv \pi_{A}^{*}-\Delta^{*}$.

The comparison between the share allocated to the platform provider and the level of profit is a little less straightforward compared to the case where renegotiation is not possible (as discussed in section 3.3). However, it can be shown that the profit for firm $A$, when implementing the first-best effort vector with the sharing rule (21) and (44), is strictly positive for $\theta=1$. Profit is strictly negative for $\theta=1 / 2$, which was the zero profit condition without renegotiation. It can also be shown that $\pi_{A}^{* *}$ continuously differentiable and strictly increasing in $\theta$, which implies that by continuity the profit for firm $A$ is also positive for $1>\theta>1 / 2$. The non-negativity condition for profit $\pi_{A}^{* *}$ when the efficient effort vector is implemented is assumed to be satisfied throughout.

From Lemmas 1' - 3' we have the following result, which differs from the equivalent result in the no-renegotiation case:

Proposition 6 Contrary to the situation where renegotiation is not possible, the platform provider will not commit to the efficient sharing rule given by (21) even if the entire value of the output is shared among the three firms, $A, B$ and $C$, since profit is always higher with the alternative sharing rule for all permissible parameter values.

Proof: If $\theta=1$, then $\pi_{A}^{* *}-\pi_{A}^{\prime}<0$, where $\pi_{A}^{* *}$ is the profit level for $A$ with shares $\left(\bar{a}_{j}, \bar{a}_{k}\right)$ to the content providers and with efficient effort levels $e^{*} \cdot \pi_{A}^{\prime}>0$ is the profit level associated with the outcome in the alternative sharing rule (28) with only a single content provider. Furthermore, $\partial\left(\pi_{A}^{* *}-\pi_{A}^{\prime}\right) / \partial \theta<0$ for $1 \geq \theta \geq$ 
$\widehat{\theta}>1 / 2$, where $\widehat{\theta} \equiv \frac{\left(\varphi b_{A}^{2}+\varphi_{A} \beta_{j}^{2}\right)\left(\varphi b_{A}^{2}+\varphi_{A} \beta_{k}^{2}\right)^{2}\left(\beta_{j}^{2}+\beta_{k}^{2}\right)}{\left(\varphi^{2} b_{A}^{4}\left(\beta_{j}^{2}+\beta_{k}^{2}\right)+\varphi_{A} \beta_{j}^{2} \beta_{k}^{2}\left(3 \varphi b_{A}^{2}+\varphi_{A} \beta_{k}^{2}\right)\right)\left(\varphi b_{A}^{2}+\varphi_{A}\left(\beta_{j}^{2}+\beta_{k}^{2}\right)\right)}$. Furthermore, $\pi_{A}^{* *}(\theta=1 / 2)-\pi_{A}^{\prime}(\theta=1 / 2)<0$ since $\pi_{A}^{* *}(\theta=1 / 2)<0$ and $\pi_{A}^{\prime}>0$ for all positive $\theta$. Thus, there is no permissible value for $\theta$ such that $\pi_{A}^{* *}-\pi_{A}^{\prime} \geq 0$. QED.

Proposition 6 tells us that the platform provider, who is one of the productive partners, will not have any incentives to implement the socially optimal sharing rule when renegotiation is possible. This is contrary to the outcome discussed in section 3.3 where renegotiation could not take place. The lack of commitment to the sharing rule that implements the first-best effort vector, (21), thus results in an inefficiency even when the entire surplus is allocated to the three productive firms. The cost of inducing the content providers to exert the socially optimal effort levels voluntarily, in essence given by (45), becomes too high.

If an intermediary firm is set up to facilitate the trade between the productive firms and end-users, we have seen that if this intermediary is in a competitive market and earning zero profit, then commitment is not an issue. The reason for this is due to the fact that the intermediary will be indifferent between the different outcomes (see also Proposition 5).

\section{Concluding remarks}

The present paper investigates a market with strictly complementary inputs, and the organisation of the distribution and sale of a bundled product to end-users. There are both productive firms (a monopoly platform provider and content providers) and an intermediary firm in the model, and the paper analyses if and how efficiency can be implemented by the use of linear sharing rules when effort is unobservable. The model is a combination of complementary team production and production in teams with substitutable efforts.

The motivation behind the model formulation has been taken (mainly) from communications markets, with the monopoly firm being a platform or distribution firm and the competitive market segment being content providers. One of the main results in the paper is that, contrary to models of complementary teams without 
competition, simple linear sharing rules cannot implement the socially efficient solution when (weak) budget balance is required. In addition, it is shown that a modified version of the group penalty sharing rule proposed by Holmstrom (1982) can implement efficiency under certain circumstances. The ability to implement first-best efficient outcomes depends both on which economic agent decides on the sharing rule and whether commitment to the rule is possible. In particular, if the (monopoly) platform provider decides on the sharing rule and renegotiation is possible, then he will not have an incentive to implement first-best as he will earn a higher level of profit with an alternative sharing rule.

\section{References}

Alchian, A. and H. Demsetz (1972), "Production, information costs, and economic organization", American Economic Review 62 (5), 777-795

Farrell, J. and S. Scotchmer (1988), "Partnerships", The Quarterly Journal of Economics 103 (2), 279-297

Holmstrom, B. (1982), "Moral hazard in teams", Bell Journal of Economics 13, 324-340

Hvide, H.K. (2001), "Some comments on free-riding in Leontief partnerships", Economic Inquiry 39 (3), 467-473

Legros, P. and S.A. Matthews (1993), "Efficient and nearly-efficient partnerships", The Review of Economic Studies 60 (3), 599-611

McAfee, R.P. and J. McMillan (1991), "Optimal contracts in teams", International Economic Review 32 (3), 561-577

Rasmussen, E. (1987), "Moral hazard in risk-averse teams", Rand Journal of Economics 18, 428-435

Vislie, J. (1994), "Efficiency and equilibria in complementary teams", Journal of Economic Behavior and Organization 23, 83-91 


\section{Appendix}

Maximising the Lagrange function given by (18) with respect to $\left(a_{B}, a_{C}\right)$ yields the following solutions:

$$
\begin{aligned}
a_{B} & =\frac{\left(\lambda \beta_{B}^{2} \varphi_{A} \varphi_{B} \varphi_{C}-\lambda b_{A}^{2} \varphi_{B}^{2} \varphi_{C}-\lambda \beta_{C}^{2} \varphi_{A} \varphi_{B}^{2}+b_{A}^{2} \beta_{B}^{2} \varphi_{B} \varphi_{C}\right)}{\beta_{B}^{2}\left(b_{A}^{2} \varphi_{B} \varphi_{C}+\varphi_{A}\left(\beta_{B}^{2} \varphi_{C}+\beta_{C}^{2} \varphi_{B}\right)\right)} \\
a_{C} & =\frac{\left(\lambda \beta_{C}^{2} \varphi_{A} \varphi_{B} \varphi_{C}-\lambda b_{A}^{2} \varphi_{B} \varphi_{C}^{2}-\lambda \beta_{B}^{2} \varphi_{A} \varphi_{C}^{2}+b_{A}^{2} \beta_{C}^{2} \varphi_{B} \varphi_{C}\right)}{\beta_{C}^{2}\left(b_{A}^{2} \varphi_{B} \varphi_{C}+\varphi_{A}\left(\beta_{B}^{2} \varphi_{C}+\beta_{C}^{2} \varphi_{B}\right)\right)}
\end{aligned}
$$

Using these sharing parameters and (11), we find the second-best optimal quality given by:

$$
q=\frac{\left(b_{A}^{2} \beta_{B}^{2} \varphi_{C}-2 \lambda b_{A}^{2} \varphi_{B} \varphi_{C}+b_{A}^{2} \beta_{C}^{2} \varphi_{B}\right)}{b_{A}^{2} \varphi_{B} \varphi_{C}+\varphi_{A}\left(\beta_{B}^{2} \varphi_{C}+\beta_{C}^{2} \varphi_{B}\right)}
$$

Using the efficiency condition (5) and (10) we find:

$$
a_{A}=\frac{\varphi_{A}\left(-2 \lambda \varphi_{B} \varphi_{C}+\beta_{B}^{2} \varphi_{C}+\beta_{C}^{2} \varphi_{B}\right)}{b_{A}^{2} \varphi_{B} \varphi_{C}+\varphi_{A}\left(\beta_{B}^{2} \varphi_{C}+\beta_{C}^{2} \varphi_{B}\right)}
$$

Solving $\left(a_{A}+a_{B}+a_{C}\right)=\theta$ for $\lambda$, we find:

$$
\lambda=\frac{\beta_{B}^{2} \beta_{C}^{2}\left((2-\theta) b_{A}^{2} \varphi_{B} \varphi_{C}+\varphi_{A}(1-\theta)\left(\beta_{B}^{2} \varphi_{C}+\beta_{C}^{2} \varphi_{B}\right)\right)}{\left(\beta_{B}^{4} \varphi_{A} \varphi_{C}^{2}+\beta_{C}^{4} \varphi_{A} \varphi_{B}^{2}+b_{A}^{2} \beta_{B}^{2} \varphi_{B} \varphi_{C}^{2}+b_{A}^{2} \beta_{C}^{2} \varphi_{B}^{2} \varphi_{C}\right)} \equiv \lambda^{*}
$$

Inserting for $\lambda=\lambda^{*}$ in $a_{A}, a_{B}$, and $a_{C}$ yields:

$$
\begin{aligned}
\widehat{a}_{A} & =\frac{\left(\beta_{B}^{4} \varphi_{A} \varphi_{C}^{2}+\beta_{C}^{4} \varphi_{A} \varphi_{B}^{2}-2(1-\theta) \beta_{B}^{2} \beta_{C}^{2} \varphi_{A} \varphi_{B} \varphi_{C}\right)}{b_{A}^{2} \varphi_{B} \varphi_{C}\left(\beta_{B}^{2} \varphi_{C}+\beta_{C}^{2} \varphi_{B}\right)+\varphi_{A}\left(\beta_{B}^{4} \varphi_{C}^{2}+\beta_{C}^{4} \varphi_{B}^{2}\right)} \\
\widehat{a}_{B} & =\frac{b_{A}^{2} \beta_{B}^{2} \varphi_{B} \varphi_{C}^{2}+(1-\theta)\left(\beta_{B}^{2} \beta_{C}^{2} \varphi_{A} \varphi_{B} \varphi_{C}-b_{A}^{2} \beta_{C}^{2} \varphi_{B}^{2} \varphi_{C}-\beta_{C}^{4} \varphi_{A} \varphi_{B}^{2}\right)}{b_{A}^{2} \varphi_{B} \varphi_{C}\left(\beta_{B}^{2} \varphi_{C}+\beta_{C}^{2} \varphi_{B}\right)+\varphi_{A}\left(\beta_{B}^{4} \varphi_{C}^{2}+\beta_{C}^{4} \varphi_{B}^{2}\right)} \\
\widehat{a}_{C} & =\frac{b_{A}^{2} \beta_{C}^{2} \varphi_{B}^{2} \varphi_{C}+(1-\theta)\left(\beta_{B}^{2} \beta_{C}^{2} \varphi_{A} \varphi_{B} \varphi_{C}-b_{A}^{2} \beta_{B}^{2} \varphi_{B} \varphi_{C}^{2}-\beta_{B}^{4} \varphi_{A} \varphi_{C}^{2}\right)}{b_{A}^{2} \varphi_{B} \varphi_{C}\left(\beta_{B}^{2} \varphi_{C}+\beta_{C}^{2} \varphi_{B}\right)+\varphi_{A}\left(\beta_{B}^{4} \varphi_{C}^{2}+\beta_{C}^{4} \varphi_{B}^{2}\right)}
\end{aligned}
$$

